\title{
The impact of the disease early warning system in responding to natural disasters and conflict crises in Pakistan
}

M. Rahim, ${ }^{7}$ B.M. Kazi, ${ }^{2}$ K.M. Bile, ${ }^{7}$ M. Munir ${ }^{1}$ and A.R. Khan ${ }^{7}$

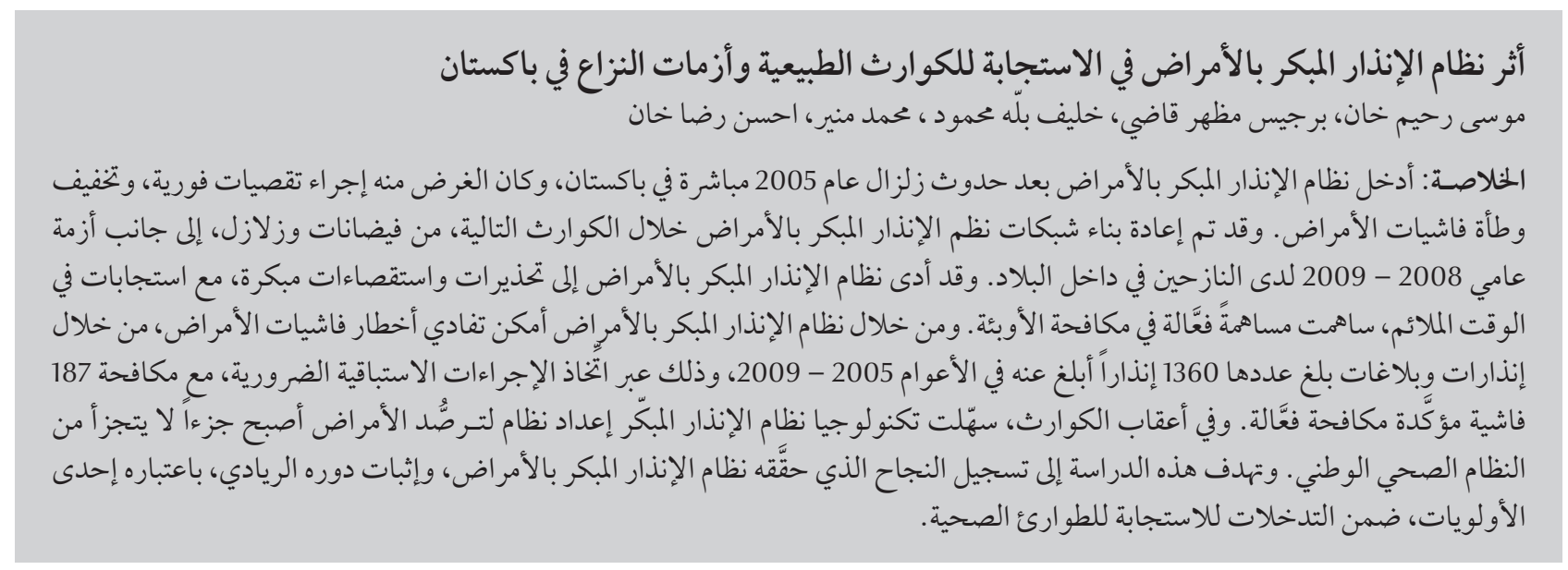

ABSTRACT The disease early warning system (DEWS) was introduced in the immediate aftermath of the 2005 earthquake in Pakistan, with the objective to undertake prompt investigation and mitigation of disease outbreaks. The DEWS network was replicated successfully during subsequent flood and earthquake disasters as well as during the 2008-09 internally displaced persons' crisis. DEWS-generated alerts, prompt investigations and timely responses had an effective contribution to the control of epidemics. Through DEWS, 1360 reported alerts during 2005-09 averted the risk of disease outbreaks through pre-emptive necessary measures, while the 187 confirmed outbreaks were effectively controlled. In the aftermath of the disasters, DEWS technology also facilitated the development of a disease-surveillance system that became an integral part of the district health system. This study aims to report the DEWS success and substantiate its lead role as a priority emergency health response intervention.

Effets du système d'alerte précoce pour les maladies sur la riposte aux crises entraînées par les catastrophes naturelles et les conflits au Pakistan

RÉSUMÉ Le système d'alerte précoce pour les maladies a été mis en place immédiatement après le tremblement de terre survenu au Pakistan en 2005, dans le but d'entreprendre des recherches et d'atténuer rapidement les flambées de maladies. Le réseau de ce système a été remis en service avec succès lors des inondations et des tremblements de terre suivants, ainsi qu'en 2008-2009 lors de la crise des déplacements internes de population. Les alertes générées par le système d'alerte précoce pour les maladies, les recherches rapides et la riposte opportune ont contribué efficacement à la lutte contre les épidémies. Grâce au système, 1360 alertes émises entre 2005 et 2009 ont permis d'éviter le risque de flambées de maladies au moyen de mesures préventives, et 187 flambées confirmées ont été endiguées de manière efficace. Suite aux différentes catastrophes, la technologie liée à ce système a également facilité la mise en place d'un système de surveillance des maladies qui fait désormais partie intégrante du système de santé des districts. Le but de cette étude est de décrire la réussite du système d'alerte précoce et de prouver son rôle déterminant en tant qu'intervention prioritaire dans la riposte sanitaire aux situations d'urgence. 


\section{Introduction}

In the past five years a range of humanitarian disasters has cumulatively affected over eight million people and mobilized enormous national and international humanitarian responses in Pakistan. The earthquake of 8 October 2005, which jolted the northern parts of the country, was the most devastating humanitarian crisis that has hit Pakistan for many decades. In June 2007, the cyclone Yemyin and flash floods devastated large parts of Sindh and Baluchistan provinces, and the situation was further exacerbated in 2008 by an earthquake that affected two districts of Baluchistan. In 2008-09, the evolving security challenges in the Federally Administered Tribal Areas (FATA) and Khyber Pakhtunkhwa resulted in the displacement of over 2.6 million people.

Massive population displacements are generally associated with high rates of mortality due to infectious diseases [1-3]. Death rates over 60 -fold from baseline have been recorded in refugee and displaced people, with over threequarters of these being caused by communicable diseases [2]. In 1994, between $6 \%$ and $10 \%$ of the Rwandan refugee population died during their early arrival in Zaire, a death rate that was two to three times higher than previous reports from Thailand, Sudan and Somalia and predominantly related to acute diarrhoeal disease outbreaks [4]. In the Darfur crisis between March 2003 and December 2008, 80\% of the estimated excess deaths (300 000) registered during the stabilization period were caused by communicable diseases such as diarrhoea [3].

Displaced populations in camp settings are at high risk of infectious diseases due to a range of risk factors that act synergistically, e.g. inadequate shelter and overcrowding, unsafe drinking water supply system, poor sanitation, poor personal hygiene, low vaccine coverage and disruption of health services [5]. A review study reported that
10 out of 11 measles' outbreaks either occurred in postconflict situations with collapsed health systems and disrupted immunization services or in settings characterized by poor or no vaccination of the target population prior to displacement; a high case fatality rate of over $5 \%$, significantly higher than that observed in a stable population, was reported from six of the nine outbreaks reviewed [6].

No fatalities were recorded among Burundian refugees in Tanzanian camps andamong tsunamivictimsin India, substantiated by the active surveillance and early case detection and management in both of these displaced populations [7]. Applying disease-control measures after an initial assessment of the emergency situation is not a guarantee that communicable diseases will not spread [8]. Conversely, the organization of an early warning system, reporting a set of selected notifiable diseases and envisaging an effective investigation and rapid diagnostic confirmation, characterizes the core strategy for the effective control of epidemics during emergencies [8-12].

DEWS is a mechanism offering prompt and early detection of potential outbreaks and providing opportunities for immediate response [13,14]. DEWS was introduced and implemented in the aftermath of the 2005 earthquake as the disease-surveillance network of choice and this successful system was replicated in subsequent disasters. Under the parameters of DEWS, a regular weekly reporting system, covering 16 selected priority diseases and conditions of public health importance, was initiated $[15,16]$. Utilizing the DEWS network, health workers were able to detect the first indication of a DEWS-notifiable disease or condition, providing the opportunity to prevent its spread and related morbidity and mortality. Every disease alert reported from any of the participating health facilities operating in the affected areas was immediately investigated and the necessary response action considered.

The objective of this paper is to review the DEWS implementation process and report the outcomes attained through this successful experience extended over four major emergencies that affected Pakistan during 2005-2009.

\section{Methods}

The DEWS data included the number of consultations and deaths disaggregated by age and gender obtained from all participating units, including public sector health facilities, improvised facilities in camps and mobile medical teams, using a standard reporting form. A computer application in Microsoft Access was utilized for data entry and analysis. The collated information included the weekly outpatient data, reported alerts and detected outbreaks during all four major emergencies in Pakistan from 2005 to 2009.

The DEWS coverage expanded with the evolving situation and the number of reporting units changed over time. To adjust to this change, the reported data were analysed by calculating the average number of detected cases, alerts and outbreaks per 100 reporting units, as a standard measure for trend analysis that was carried out for four main diseases, measles, acute watery diarrhoea, acute jaundice syndrome and dengue fever, as they accounted for the majority of the reported alerts and detected outbreaks.

\section{Results}

The DEWS network was implemented within two weeks following the 2005 earthquake and covered the affected districts in close collaboration with the Ministry of Health, the Government of Pakistan Administered Kashmir (PAK) and Khyber Pakhtunkhwa province and health cluster partners. Standard case definitions were clearly outlined and 
alert and outbreak thresholds for the priority notifiable diseases and conditions explicitly defined, to ensure uniformity of reporting, timeliness and detection accuracy and to undertake immediate control measures when necessary.

Table 1 illustrates the alert and outbreak thresholds for the priority diseases and conditions under DEWS surveillance. These stated definitions and thresholds improved the sensitivity of reporting and impacted on the promptness of response interventions.

An exhaustive surveillance network was established and expanded, covering all the functioning health facilities in the affected districts. The number of reporting sites in the 2005 earthquakeaffected districts had increased from an initial 19 to 133 by December 2005 . The same DEWS network was established in all subsequent disasters, such as the floods in Sindh and Baluchistan, the
2008 earthquake in Baluchistan and the 2008-2009 internally displaced persons (IDPs) crisis in FATA and Khyber Pakhtunkhwa. By December 2009, the DEWS network had expanded to 1319 health facilities in 50 emergency-affected districts. From October 2005 to December 2009, more than 28 million consultations were recorded, with acute respiratory infection being the leading cause and accounting for around seven million (25\%) consultations, followed by acute diarrhoea $(8 \%)$, suspected malaria (5\%) and scabies (5\%).

Figure 1 illustrates the framework of the sequential tasks and related support, and capacity-building activities relevant to DEWS. All detected alerts led to verification, investigation, confirmation and mitigation response interventions. Investigation results uncovered misdiagnoses, detection of cases below the epidemic threshold level or confirmed evident outbreaks.

DEWS teams were deployed in the target districts to develop the surveillance network infrastructure and train health care providers on standard case definitions, data collection and reporting, including alerts, and to initiate an immediate response when outbreaks were confirmed. The district health offices were supported with information technology equipment and software for data collection and management. Contingency stockpiling of medicines and supplies was organized at strategic district locations to ensure a prompt and effective response. Sample collection and transportation were also facilitated to access the specialized laboratory facilities of the National Institute of Health, Islamabad, a World Health Organization (WHO) collaborating centre.

\begin{tabular}{|c|c|c|}
\hline \multirow[t]{2}{*}{ Disease/condition } & \multicolumn{2}{|c|}{ Thresholds } \\
\hline & Alerts & Outbreaks \\
\hline $\begin{array}{l}\text { Acute lower respiratory } \\
\text { infection }\end{array}$ & $\begin{array}{l}\text { Twice the average number of cases of the previous } \\
\text { three weeks for a given location }\end{array}$ & $\begin{array}{l}\text { Clustering of cases in a single location above the } \\
\text { alert threshold }\end{array}$ \\
\hline $\begin{array}{l}\text { Acute upper respiratory } \\
\text { infection }\end{array}$ & $\begin{array}{l}\text { Twice the average number of cases of the previous } \\
\text { three weeks for a given location }\end{array}$ & Not specified until infectious agent is identified \\
\hline $\begin{array}{l}\text { Acute diarrhoea (non } \\
\text { cholera) }\end{array}$ & $\begin{array}{l}\text { Twice the average number of cases of the previous } \\
\text { three weeks for a given location }\end{array}$ & $\begin{array}{l}\text { Clustering of cases in a single location above the } \\
\text { alert threshold }\end{array}$ \\
\hline $\begin{array}{l}\text { Acute watery diarrhoea } \\
\text { (suspected cholera) }\end{array}$ & One suspected case & $\begin{array}{l}\text { A confirmed case, or a cluster of three or more } \\
\text { suspected cases in a single locality }\end{array}$ \\
\hline Bloody diarrhoea & Three or more cases in one location & $\begin{array}{l}\text { Doubling of case-load from alert threshold in } \\
\text { one location }\end{array}$ \\
\hline Haemorrhagic fever & One probable case & One confirmed case \\
\hline Acute jaundice syndrome & Three or more cases in one location & A cluster of 8-10 cases in one location \\
\hline Malaria & $\begin{array}{l}\text { Twice the average number of cases of the previous } \\
\text { three weeks for a given location }\end{array}$ & $\begin{array}{l}\text { Clustering of cases in a single location above the } \\
\text { alert threshold }\end{array}$ \\
\hline Measles & One case & Five or more cases in a single location \\
\hline Meningococcal meningitis & One case & $\begin{array}{l}\text { Two or more confirmed cases from a single } \\
\text { location }\end{array}$ \\
\hline Acute flaccid paralysis & One suspected case & One confirmed case \\
\hline Unexplained fever & $\begin{array}{l}\text { One death or twice the average number of cases of } \\
\text { the previous three weeks for a given location }\end{array}$ & Not specified until infectious agent is identified \\
\hline Neonatal tetanus & $\begin{array}{l}\text { One case requires investigation for safe birth } \\
\text { practices }\end{array}$ & None (does not spread) \\
\hline Scabies & $\begin{array}{l}\text { Twice the average number of cases of the previous } \\
\text { three weeks for a given location }\end{array}$ & $\begin{array}{l}\text { To be determined by trends (recently added to } \\
\text { surveillance) }\end{array}$ \\
\hline
\end{tabular}




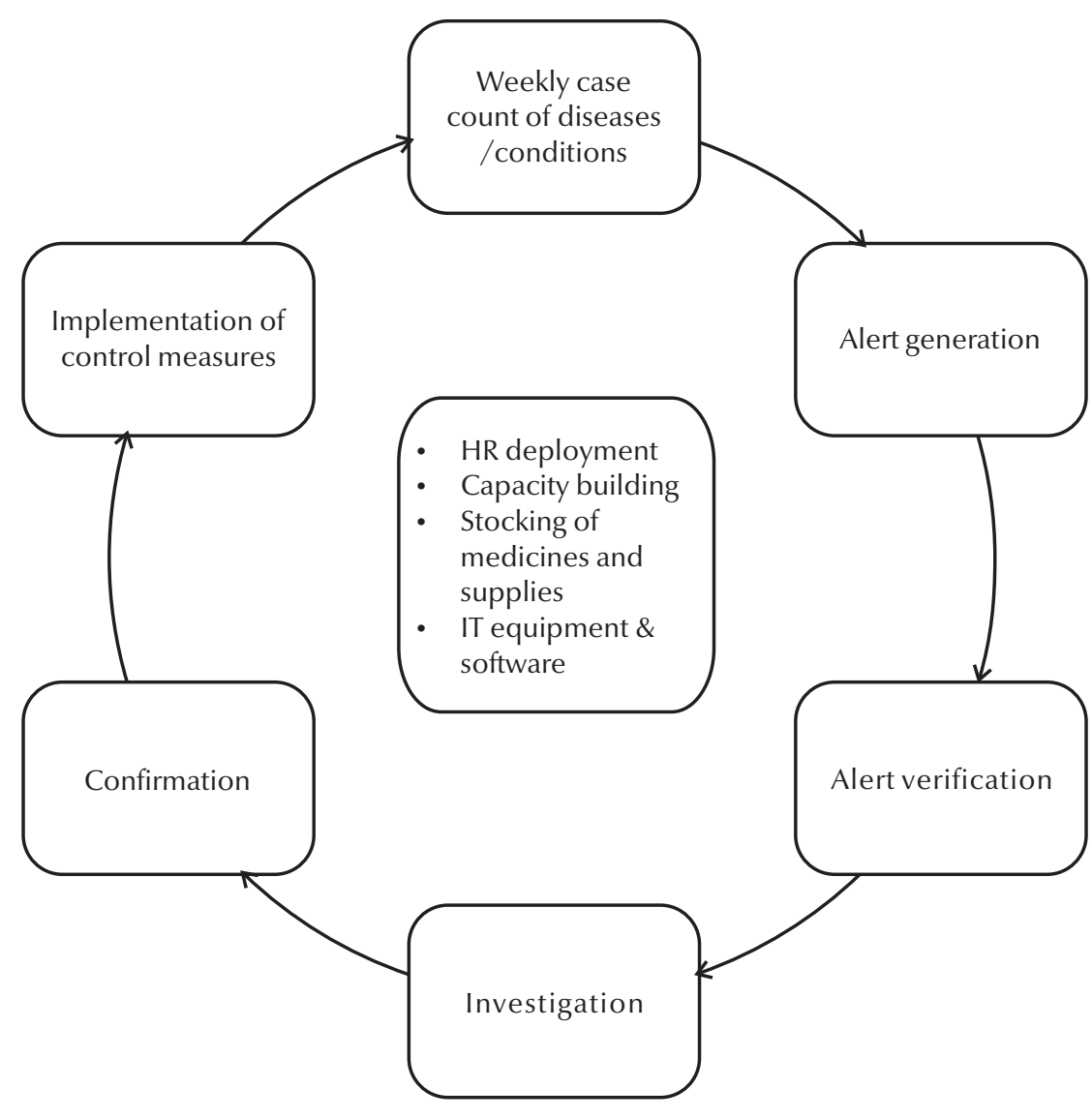

Figure $1 \mathrm{~A}$ framework of disease early warning system (DEWS) sequential tasks and related support and capacity-building activities

Table 2 illustrates the alerts and outbreaks reported for each disease or condition by type of emergency and the affected area from November 2005 to December 2009. During this period a cumulative total of 1368 alerts was reported from disaster-affected regions, and investigation, prompt epidemic response and control interventions were carried out for all the 187 identified outbreaks.

Through the DEWS network, 46 alerts and 18 outbreaks were reported that were caused by diseases not included in the priority notifiable communicable diseases and conditions. Although outside the recognized notifiable disease list, all the alerts and outbreaks were investigated and control measures introduced as appropriate. These included avian influenza, influenza $\mathrm{H} 1 \mathrm{Nl}$, cutaneous leishmaniasis, chicken pox,
Laboratory support was provided to confirm the diagnosis and expedite field investigations. For suspected cholera, 373 stool samples were collected, of which Vibrio cholerae was confirmed in 157 (42\%). Blood samples from 190 suspected cases of measles were tested serologically at the National Institute of Health and 125 (66\%) samples were confirmed. For acute viral hepatitis, 189 blood samples were tested for laboratory diagnosis. Of these, hepatitis A was confirmed in 54 (29\%) samples (36 sporadic cases and 18 samples from outbreak settings) and hepatitis $\mathrm{E}$ in 44 (23\%) samples (30 from outbreak settings and 14 diagnosed as sporadic cases).

Figure 2 illustrates the monthly trends for acute diarrhoeal disease, acute respiratory infection and measles from the onset of the earthquake till 2009.

Acute watery diarrhoea, measles, dengue fever and acute jaundice syndrome (viral hepatitis) accounted for $56 \%$ of the alerts and $83 \%$ of the outbreaks. Detailed analysis of the outbreaks and reported cases, standardized per 100 reporting units, showed that outbreaks of acute watery diarrhoea declined in all the emergency-affected areas although the seasonal incidence of diarrhoeal diseases was sustained. In the 2005 post-earthquake period, there were 20 outbreaks in the year 2006, followed by eight, two and one outbreak in 2007, 2008 and 2009, respectively. The measles outbreaks and cases recorded in the subsequent years following the earthquake were significantly less frequent compared with the disease occurrence during the first year of the disaster [odds ratio $(\mathrm{OR})=0.04 ; 95 \%$ confidence interval (CI): 0.00-0.30. In the 2005 post-earthquake disaster, 17 measles outbreaks were confirmed in 2006 and three outbreaks were detected in 2007 but no measles outbreaks were recorded subsequently. In the floodaffected areas of Sindh and Baluchistan, and among the IDPs in FATA and 


\begin{tabular}{|c|c|c|c|c|c|c|c|c|c|c|c|c|}
\hline \multirow[t]{4}{*}{$\begin{array}{l}\text { Diseases/ } \\
\text { conditions }\end{array}$} & \multirow{2}{*}{\multicolumn{2}{|c|}{$\begin{array}{l}\text { Earthquake, } \\
\text { PAK and Khyber } \\
\text { Pakhtunkhwa } \\
\text { Nov. 05-Dec. } 09\end{array}$}} & \multicolumn{2}{|c|}{$\begin{array}{l}\text { Floods, } \\
\text { Sindh }\end{array}$} & \multicolumn{2}{|c|}{$\begin{array}{l}\text { Floods and } \\
\text { earthquake, } \\
\text { Baluchistan }\end{array}$} & \multicolumn{2}{|c|}{$\begin{array}{l}\text { IDP crisis, } \\
\text { Khyber } \\
\text { Pakhtunkhwa }\end{array}$} & \multicolumn{4}{|c|}{ Total } \\
\hline & & & Aug. 0 & 7-Dec. 09 & Aug. 0 & 7-Dec. 09 & Aug. 0 & 8-Dec. 09 & & & & \\
\hline & Alerts & Outbreaks & Alerts & Outbreaks & Alerts & Outbreaks & Alerts & Outbreaks & & lerts & Out & breaks \\
\hline & No. & No. & No. & No. & No. & No. & No. & No. & No. & $\%$ & No. & $\%$ \\
\hline Acute flaccid paralysis & 102 & 0 & 73 & 1 & 7 & 0 & 16 & 1 & 198 & 14.47 & 2 & 1.06 \\
\hline $\begin{array}{l}\text { Acute jaundice } \\
\text { syndrome }\end{array}$ & 142 & 16 & 40 & 0 & 0 & 0 & 4 & 0 & 186 & 13.59 & 16 & 8.55 \\
\hline $\begin{array}{l}\text { Acute respiratory } \\
\text { infection }\end{array}$ & 17 & 1 & 6 & 1 & 0 & 0 & 0 & 0 & 23 & 1.68 & 2 & 1.06 \\
\hline $\begin{array}{c}\text { Acute watery } \\
\text { diarrhoea }\end{array}$ & 122 & 33 & 66 & 13 & 13 & 9 & 60 & 30 & 261 & 19.07 & 85 & 45.45 \\
\hline Bloody diarrhoea & 42 & 3 & 15 & 0 & 2 & 0 & 5 & 3 & 64 & 4.67 & 6 & 3.20 \\
\hline $\begin{array}{l}\text { Crimean-Congo } \\
\text { haemorrhagic fever }\end{array}$ & 4 & 0 & 0 & 0 & 0 & 0 & 2 & 1 & 6 & 0.43 & 1 & 0.53 \\
\hline $\begin{array}{l}\text { Dengue } \\
\text { haemorrhagic fever }\end{array}$ & 20 & 3 & 24 & 13 & 0 & 0 & 11 & 5 & 55 & 4.02 & 21 & 11.22 \\
\hline Unexplained fever & 3 & 0 & 0 & 0 & 0 & 0 & 0 & 0 & 3 & 0.21 & 0 & 0 \\
\hline Malaria & 24 & 1 & 5 & 1 & 3 & 0 & 3 & 0 & 35 & 2.55 & 2 & 1.06 \\
\hline Measles & 199 & 26 & 31 & 2 & 11 & 1 & 25 & 4 & 266 & 19.44 & 33 & 17.64 \\
\hline Meningitis & 101 & 1 & 51 & 0 & 0 & 0 & 1 & 0 & 153 & 11.18 & 1 & 0.53 \\
\hline Tetanus & 3 & 0 & 1 & 0 & 0 & 0 & 0 & 0 & 4 & 0.29 & 0 & 0 \\
\hline Neonatal tetanus & 5 & 0 & 61 & 0 & 1 & 0 & 1 & 0 & 68 & 4.97 & 0 & 0 \\
\hline Others & 14 & 7 & 3 & 3 & 0 & 0 & 29 & 8 & 46 & 3.36 & 18 & 9.62 \\
\hline Total & 798 & 91 & 376 & 34 & 37 & 10 & 157 & 52 & 1368 & 100 & 187 & 100 \\
\hline
\end{tabular}

PAK = Pakistan Administered Kashmir; IDP = internally displaced persons.

Khyber Pakhtunkhwa, a declining measles trend was observed, though this was not significant.

During the four-year surveillance in all disaster-affected areas, no significant decline was observed in the number of outbreaks or case-load of dengue fever, or change in the seasonality of the disease occurrence. In the 2005 earthquake-affected area, acute jaundice syndrome cases dropped gradually and significantly over the subsequent years as compared with the first postearthquake year $(\mathrm{OR}=0.18$; $95 \% \mathrm{CI}$ : 0.11-0.30).Inthe 2005 post-earthquake period, there were nine acute jaundice syndrome outbreaks in 2006, followed by three and two outbreaks in 2007 and 2008, respectively, while no outbreaks were detected in 2009 .

\section{Discussion}

Communicable diseases are of major public health concern in Pakistan, with yearly outbreaks of waterborne, vector-borne and vaccine-preventable diseases that worsen during emergencies $[1,10,17]$. The prompt establishment of DEWS immediately after the October 2005 earthquake led to the early detection of potential outbreaks and prompted rapid control interventions that prevented a large number of alerts evolving into full-blown disease outbreaks, mitigating the risk among this vulnerable population. Drawing experience from this successful lesson, the DEWS surveillance network was replicated in subsequent emergencies in Pakistan.
The close collaboration of the Ministry of Health and health cluster partners in DEWS implementation ensured its acceptability, technical soundness and practical viability [17]. Alerts and outbreaks for priority diseases were frequently detected and controlled effectively, including those encountered but not officially recognized as DEWSnotifiable diseases, e.g. avian influenza, influenza H1N1 and leishmaniasis. As reported from previous humanitarian interventions elsewhere, the majority of outbreaks in Pakistan were encountered at the outset of the emergencies [1]. The successful implementation of the DEWS network in subsequent emergencies was substantiated by the merit of its operational feasibility, effective disease-control impact, acceptability to the health cluster partners and generous 

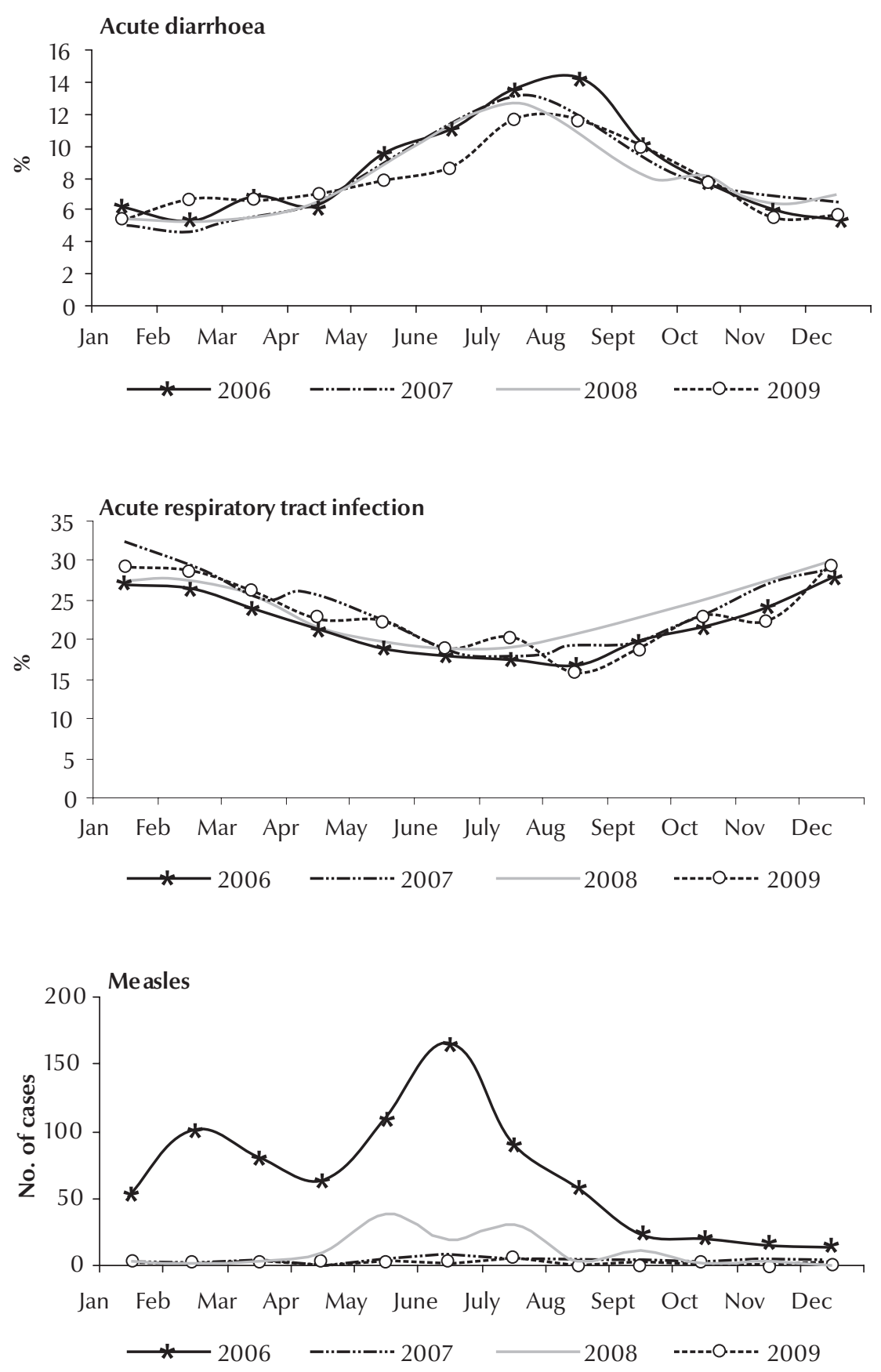

Figure 2 Monthly trends of acute diarrhoea, acute respiratory infection and measles following the $\mathbf{2 0 0 5}$ earthquake prospectively recorded for a period of four years (2006-09)

funding support by international partners during the course of its implementation.

Acute watery diarrhoea (cholera) and measles outbreaks were detected from most of the emergency-affected areas and effective control measures were introduced. Dengue fever outbreaks the multiple unprotected water supply sources and the difficulty in improving drinking water safety for a large and widely scattered population, as was the case in the post-earthquake period. Hepatitis A cases were detected more frequently in the population age group of less than 15 years, while hepatitis $\mathrm{E}$ was more predominant in the older age bracket, consistent with the epidemiology of these diseases. Two outbreaks of cutaneous leishmaniasis were identified in the IDP-crisis affected area and control measures were undertaken

The occurrence of communicable disease outbreaks was influenced by a complex interplay of host, agent and environment-related factors $[8,17,18]$. Setting priorities for disease surveillance and risk assessment during humanitarian emergencies therefore required a careful consideration of the potential interaction of all three factors consistent with the specific geographical context and prevailing epidemiological vulnerability of the population $[16,19]$.

The declining rate of measles over time was partly attributed to the vaccination campaigns carried out in the immediate aftermath of every disaster. This initial large-scale effort was further augmented by the robust surveillance system and mop-up vaccination campaigns conducted wherever a clustering of cases was reported. Through the expansion of DEWS in 2006, measles outbreaks were detected from remote areas that did not benefit from the earlier mass vaccination campaigns in the 2005 earthquake-affected area. The two-dose vaccination strategy for the target child population may be considered during emergencies for effective immunization and disease prevention while all efforts need to be made to reach out to remote localities where the impact of disease outbreaks would be more devastating.

The higher frequency of waterborne diseases can be explained by the complexity of the interventions necessary to change the unfavourable hygienic and environmental conditions that allow 
these diseases to spread. Undoubtedly, lack of clean water is the most obvious risk of infection and disease outbreak. The latter was related to the use of unprotected water sources or unhygienic vessels for the transportation and storage of water at homes and to the intermittent piped water distribution system that posed high risk of sewage contamination in most of the affected towns $[5,20]$. To monitor water quality, field water testing kits were introduced to isolate the source of contamination and implement the necessary control interventions. Health and hygiene promotion was also carried out through behaviourchange communication interventions alongside improvements in the water supply infrastructure.

The successful implementation of DEWS was helped by the cooperation between health cluster partners and the national and provincial health system. Confidence in the system has contributed to DEWS' active case finding, prompt reporting ability, close analysis of disease trends and early mitigation and outbreak control. In the first post-earthquake year, $10 \%$ of the 336 reported alerts were received late, while the delayed alerts in the second and third years were $6 \%$ and
$2 \%$, respectively, illustrating the capacity of the system to control epidemics. To sustain the technical role of DEWS, trained human resources, the necessary infrastructure and strong analytical and response backup support capacities, including laboratory diagnostics, need to be ensured. The mobilization of these operational capacities was the key asset that led to the remarkable prevention and control of epidemics during emergency response interventions in Pakistan. The DEWS technology was further developed by introducing a new software package with automated surveillance bulletins, alert notification and disease-trend plotting, facilitating the work of surveillance officers and enhancing their ability to detect potential outbreaks

A major contribution of DEWS was the concurrent capacity building of local human resources, where district teams were trained on disease surveillance, alert/outbreak investigation and response. This process has enabled the district health system to sustain DEWS surveillance, epidemic detection and control capacity beyond the disaster period.

Sensitive disease-surveillance systems are absolutely essential for the detection and control of communicable disease outbreaks and for averting avoidable morbidity and mortality in the disaster-affected populations. The DEWS initiative can be organized within a week and implemented effectively in all disaster-affected areas, despite the initial lack of accurate population data, limited communication network for data collection, scarcity of reliable laboratory services, absence of prior logistic arrangements for the timely dispatch of samples to a reference laboratory and the early coordination challenge with health partners. The latter substantiates the robustness, reliability and effectiveness of this system, in an environment where health services are disrupted, their capacities overwhelmed and where the prevention of epidemics becomes both a life-saving entity as well as a coping necessity for the health system by lowering the burden of disease. DEWS has become an effective, tested strategy for the control of communicable disease outbreaks and epidemics during emergencies. The interest shown by the health management teams to sustain DEWS in the post-emergency period was also supported by WHO to make it an integral component of the district health system capacity development.

\section{References}

1. Paquet $\mathrm{C}$, Hanquet G. Control of infectious diseases in refugee and displaced populations in developing countries. Bulletin de l'Institut Pasteur, 1998, 96:3-14.

2. Connolly $\mathrm{M}$ et al. Communicable diseases in complex emergencies: impact and challenges. Lancet, 2004, 364:1974-1983.

3. Degomme O, Debarati GS. Pattern of mortality rates in Darfur conflict. Lancet, 2010, 375:294-300.

4. Goma Epidemiology Group. Public health impact of Rwandan refugee crisis: what happened in Goma, Zaire, in July 1994? Lancet, 1995, 345:339-343.

5. Toole MJ, Waldman. RJ. An analysis of mortality trends among refugee populations in Somalia, Sudan and Thailand. Bulletin of the World Health Organization, 1988, 66(2):237-247.

6. Kouadio IK, Kamigaki T, Oshitani H. Measles outbreaks in displaced populations: a review of transmission, morbidity and mortality associated factors. BMC International Health and Human Rights, 2010, 10:5.
7. Mohan A et al. Measles transmission following the tsunami in a population with a high one-dose vaccination coverage, Tamil Nadu, India 2004-2005. BMC Infectious Diseases, 2006, 6:143.

8. Abdallah S, Burnham G. Public health guide for emergencies: control of communicable diseases. United States of America, The Johns Hopkins School of Hygiene and Public Health and The International Federation of Red Cross and Red Crescent Societies (http://pdf.usaid.gov/pdf_docs/PNACU086.pdf, accessed 6 April 2010).

9. Connolly MA, ed. Communicable disease control in emergencies: a field manual. Geneva, World Health Organization, 2005 (WHO/CDS/2005.27).

10. Connolly MA, Heymann DL. Deadly comrades: war and infectious diseases. Lancet, 2002, 360 (Suppl.):S23-S24.

11. Watson JT, Gayer M, Connolly MA. Epidemics after natural disasters. Emerging Infectious Diseases, 2007, 13(1):1-5.

12. Marfin AA et al. Infectious disease surveillance during emergency relief to Bhutanese refugees in Nepal. Journal of the American Medical Association, 1994, 272(5):377-381. 
13. Valenciano $\mathrm{M}$ et al. Challenges for communicable disease surveillance and control in Southern Iraq, April-June 2003. Journal of the American Medical Association, 2003, 290(5):654-658.

14. Guidelines for disease surveillance/early warning and response: Middle East crisis. Geneva, World Health Organization, 2006 (WHO/CDS/NTD/DCE/2006.6) http://www.who.int/diseasecontrol_emergencies/guidelines/Middle\%20East\%20 Crisis_WHO\%20CD\%20surveillance_early\%20warning\%20 guidelines.pdf, accessed 27 June 2010).

15. South Asia earthquake-affected areas, 2005: operational plan and communicable diseases surveillance/early warning and response guidelines. Islamabad, Ministry of Health Pakistan and World Health Organization, 2005 (http://www.whopak.org/ pdf/PostAsiaearthquakeCDrisksinterventions.pdf, accessed 19 January 2010).
16. Communicable disease risk assessment: protocol for humanitarian emergencies. Geneva, World Health Organization, 2007 (WHO/CDS/NTD/DCE/2007.4).

17. Noji EK. ABC of conflict and disaster: public health in aftermath of disasters. British Medical Journal, 2005, 330:1379-1381.

18. Epidemic-prone disease surveillance and response after the tsunami in Aceh province, Indonesia. Weekly Epidemiological Record, 2005, 80(18):157-164.

19. Setting priorities in communicable disease surveillance. Geneva, World Health Organization, 2006 (WHO/CDS/EPR/ LYO/2006.3).

20. Lee E J, Schwab K J. Deficiencies in drinking water distribution systems in developing countries. Journal of Water and Health, 2005, 3(2):109-127. 